ARTICLE

https://doi.org/10.1038/s41467-019-12766-6

\title{
Dynamic multiphase semi-crystalline polymers based on thermally reversible pyrazole-urea bonds
}

Wen-Xing Liu (10 ${ }^{1,3}$, Zhusheng Yang ${ }^{1}$, Zhi Qiao ${ }^{1}$, Long Zhang ${ }^{2 \star}$, Ning Zhao ${ }^{1 \star}$, Sanzhong Luo ${ }^{2} \&$ Jian Xu (i) $^{1 \star}$

Constructing responsive and adaptive materials by dynamic covalent bonds is an attractive strategy in material design. Here, we present a kind of dynamic covalent polyureas which can be prepared from the highly efficient polyaddition reaction of pyrazoles and diisocyanates at ambient temperature in the absence of a catalyst. Owing to multiphase structural design, poly (pyrazole-ureas) (PPzUs) show excellent mechanical properties and unique crystallization behavior. Besides, the crosslinked PPzUs can be successfully recycled upon heating $\left(\sim 130{ }^{\circ} \mathrm{C}\right)$ and the molecular-level blending of polyurea and polyurethane is realized. Theoretical studies prove that the reversibility of pyrazole-urea bonds (PzUBs) arises from the unique aromatic nature of pyrazole and the $\mathrm{N}$-assisting intramolecular hydrogen transfer process. The PzUBs could further broaden the scope of dynamic covalent bonds and are very promising in the fields of dynamic materials.

\footnotetext{
${ }^{1}$ Beijing National Laboratory for Molecular Sciences (BNLMS), Laboratory of Polymer Physics and Chemistry, Institute of Chemistry, Chinese Academy of Sciences, Beijing 100190, China. ${ }^{2}$ Center of Basic Molecular Science (CBMS), Department of Chemistry, Tsinghua University, Beijing 100084, China.

${ }^{3}$ Present address: Department of Organic Chemistry, University of Geneva, Geneva CH-1211, Switzerland. *email: zhanglong@iccas.ac.cn; zhaoning@iccas.ac. cn; jxu@iccas.ac.cn
} 
D ynamic polymer materials, which rely on the covalent bonds capable of undergoing the reversible formation and cleavage under appropriate conditions, are able to reorganize their macromolecular architectures or compositions, and thus produce a macroscopic response to the environment and surrounding stimuli ${ }^{1-3}$. In recent years, great efforts have been made to create complex, smart, and adaptive polymeric materials that allow access to topological/constitutional structure transformation $^{4}$, controlled assembly ${ }^{5}$, shape memory 6,7 , self-healing, and recyclability ${ }^{8-33}$, to name a few. Although in this context, the library of dynamic polymers has extended rapidly, it remains a challenge to design mechanically robust dynamic polymers with high strength, extensionality, and malleability.

Isocyanate-based polymers, polyureas, or polyurethanes, are widely used in coatings, elastomers, adhesives, foams, and fibers ${ }^{34}$. Recently, by introducing oxime moiety into urethane bonds, we developed the dynamic poly(oxime-urethanes) (POUs) ${ }^{35}$, which have shown excellent self-healing ability, malleability, and mechanical properties ${ }^{31,35}$. Compared with urethane bonds, urea bonds are more stable and irreversible due to the dual resonance stabilized structure. Typically, the neutral hydrolysis half-time of polyureas is $>10^{4}$ years ${ }^{36}$. Harsh conditions are required to cleave urea bonds, such as acidic or basic solutions, high temperature, and catalysts ${ }^{37-39}$, which limits their applications in dynamic covalent materials. Metal catalyst such as zinc acetate shows effectiveness to increase the reversibility of normal urea bonds ${ }^{40}$. In addition, by introducing bulky substituents to a urea nitrogen atom, the hindered urea bonds are significantly destabilized owing to the steric inhibition of resonance via hindering the orbital coplanarity of the urea bond, thus resulting in reversibly dissociating to isocyanate and amine under ambient condition without a catalyst $^{41-43}$. However, due to the high sensitivity of isocyanate intermediate to moisture, this system may suffer from high susceptibility to hydrolysis ${ }^{43}$.

As stable aromatic heterocyclic compounds, pyrazoles have been used as building blocks in some material fields ${ }^{44,45}$. Owing to the aromaticity of pyrazoles, opposed resonance occurs in pyrazole-amide bonds and the conjugation effect between the pyrazole nitrogen and the carbonyl group is slightly diminished (Fig. 1a) ${ }^{46}$. This interesting $N$-acylpyrazole chemistry inspires us that pyrazole may be a potential candidate for the design of dynamic amide-containing polymers.

Here, we present the reversible pyrazole-urea bonds (PzUBs), which are applied for the design of a series of mechanically robust dynamic polymers, poly(pyrazole-ureas) (PPzUs). PPzUs are stable at room temperature, and spontaneously reversible at elevated temperatures. Unlike previously reported dynamic polymers, whose crystallization is inhibited because of structure design with bulky monomers or high-cross-linking density, the highly cross-linked $\mathrm{PPzU}$ thermosets are semi-crystalline polymers. The crystallization behavior of PPzUs offers substantial advantages in terms of strength, toughness, and solvent resistance in contrast to the amorphous dynamic polymers.

\section{Results}

Dynamic chemistry of pyrazole-urea bonds. Although kinetic and thermodynamic behaviors are the underlying features of dynamic reactions, these chemical characteristics of PzUBs have not been studied up to now ${ }^{47,48}$. We first investigated the addition reaction between octyl isocyanate $\mathbf{1 b}$ and 4-methylpyrazole 1c (Fig. 1b), whose rate was monitored through the change of NCO infrared absorption. The reaction could almost proceed to completion within $25 \mathrm{~min}$ at $30^{\circ} \mathrm{C}$ in various aprotic solvents, with the second binding rate constants $k_{\mathrm{b}}$ in the range of $4.2-9.7 \times 10^{-2} \mathrm{M}^{-1} \mathrm{~s}^{-1} \quad\left(\right.$ rate $=k_{\mathrm{b}}$ [NCO][pyrazole],
Supplementary Figs. 1-2) and an Arrhenius activation energy $E_{\mathrm{a}, \mathrm{b}}$ of $11.3 \mathrm{kcal} \mathrm{mol}^{-1}$ (Table 1; Supplementary Fig. 3). What is more, PzUBs show good stability at ambient temperature (Supplementary Fig. 4). However, a $6 \%$ thermal dissociation of $\mathbf{1 b c}$ was obtained in several minutes by ${ }^{1} \mathrm{H}$ NMR at $110^{\circ} \mathrm{C}$ with a dissociation equilibrium constant $K_{\mathrm{d}}$ of $1.3 \times 10^{-3} \mathrm{M}$ and a dissociation enthalpy $\Delta H_{\mathrm{d}}$ of $18.5 \mathrm{kcal} \mathrm{mol}^{-1}$ (Table 1; Supplementary Fig. 5).

Then a more detailed mechanism investigation was undertaken by using aryl substituted pyrazole-ureas and exploring thermodynamics of their thermal dissociation reactions. A Hammett analysis of the dissociation equilibriums revealed that the dissociation step is hindered by electron-withdrawing groups, such as $\mathrm{Cl}$ and $\mathrm{CF}_{3}$ (Supplementary Fig. 6). A linear free energy relationship was found with a negative reaction slope $(\rho=-1.0)$, indicating that a fast proton transfer may occur first in the reversed process and the $\mathrm{C}-\mathrm{N}$ bond breaking step is ratedetermining during which the negative charge on the urea moiety is dramatically reduced.

To quantify the kinetics of the dissociation reaction, the exchange reaction of $\mathbf{1} \mathbf{a c}$ and $\mathbf{1 b d}$ to produce $\mathbf{1} \mathbf{a d}$ and $\mathbf{1 b c}$ was followed by liquid chromatography at different temperatures (Fig. 1c; Supplementary Fig. 7). As expected, the equilibrium mixture containing equimolar amounts of all four pyrazole-ureas was obtained after $150 \mathrm{~min}$ at $120^{\circ} \mathrm{C}$ or $2000 \mathrm{~min}$ at $90^{\circ} \mathrm{C}$. Besides, the dissociation rate constant $k_{\mathrm{d}}$ of $0.12 \mathrm{~h}^{-1}$ at $90^{\circ} \mathrm{C}$ and the dissociation activation energy $E_{\mathrm{a}, \mathrm{d}}$ of $26.0 \mathrm{kcal} \mathrm{mol}^{-1}$ were found (Table 1, Supplementary Figs. 8-9), which are close to those of other thermally reversible bonds ${ }^{1,8,35}$. Above studies show that PzUBs with fast formation process and good stability at room temperature can undergo evidently thermal reversibility without any catalyst.

Theoretical studies. Density functional theory (DFT) calculations were performed to gain further insight into the formation and dynamic nature of $\mathrm{PzUBs}$ with pyrazole and methyl isocyanate (MeNCO) as model reactants at the theory level of B3LYP/6$311++\mathrm{G}(2 \mathrm{df}, 2 \mathrm{pd}) / / \mathrm{B} 3 \mathrm{LYP} / 6-31+\mathrm{G}(\mathrm{d}, \mathrm{p})$. Theoretical studies indicated that after the formation of a complex between pyrazole and isocyanate, nucleophilic attack of the pyridine-type nitrogen in pyrazole to MeNCO, via transition state TS1 with an activation enthalpy of $12.8 \mathrm{kcal} \mathrm{mol}^{-1}$ and an activation free energy of 24.4 $\mathrm{kcal} \mathrm{mol}^{-1}$, leads to intermediate Int2 $\left(3.7 \mathrm{kcal} \mathrm{mol}^{-1}\right.$ below TS1). The subsequent proton shift process smoothly produces pyrazole-urea P1 with an activation enthalpy of $3.3 \mathrm{kcal} \mathrm{mol}^{-1}$, which is exothermic by $23.0 \mathrm{kcal} \mathrm{mol}^{-1}$. According to these calculations, this pathway with nucleophilic addition as rate-limiting step accords with the first-order kinetics for both pyrazole and isocyanate as well as the Hammett analysis (Supplementary Figs. 1 and 6), and the reverse reaction requires an activation enthalpy of $27.9 \mathrm{kcal} \mathrm{mol}^{-1}$ (Fig. 2a). These activation parameters are close to those obtained by experiments (Supplementary Figs. 10-11, Supplementary Tables 1-2).

For further consideration, resonance energies $\left(E_{\mathrm{R}}\right)$ of the amide bond in different ureas were calculated to account for the distinctions in dynamicity at the level of B3LYP/6-31 + G(d) (Fig. 2b $)^{49}$. Resonance energy in pyrazole-urea $\left(5.6 \mathrm{kcal} \mathrm{mol}^{-1}\right)$ is lower than that in normal urea $\left(7.2 \mathrm{kcal} \mathrm{mol}^{-1}\right)$, but is higher than that in hindered urea $\left(3.9 \mathrm{kcal} \mathrm{mol}^{-1}\right)$, which is consistent with the relative stability of the corresponding ureas. Therefore, the compatibility of stability and reversibility of PzUBs originates from the aromatic character of pyrazole moderately weakening the resonance stabilization and the presence of adjacent nitrogen atom facilitating the intramolecular 1,4-hydrogen transfer process (Supplementary Figs. 12-14). 
a

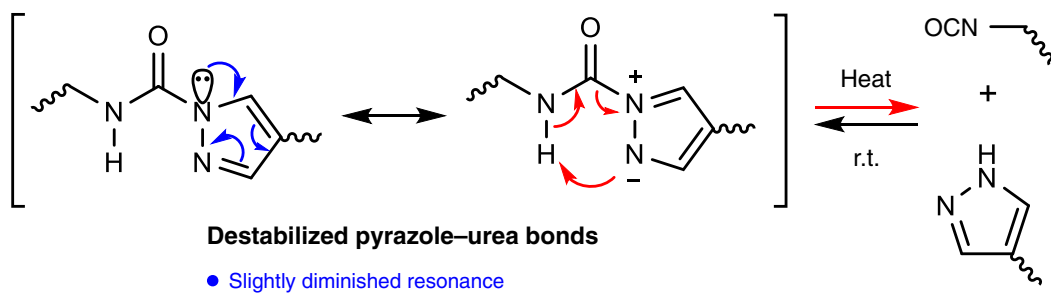

- Intramolecular 1,4-hydrogen transfer

b

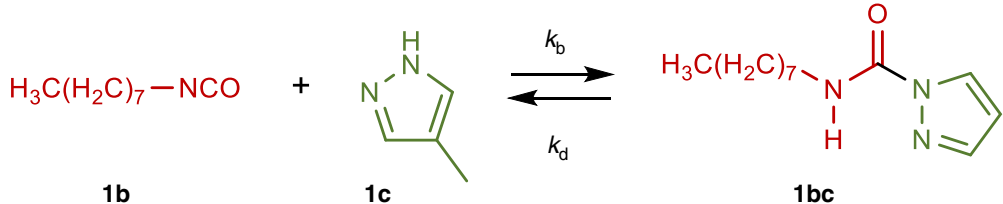

C
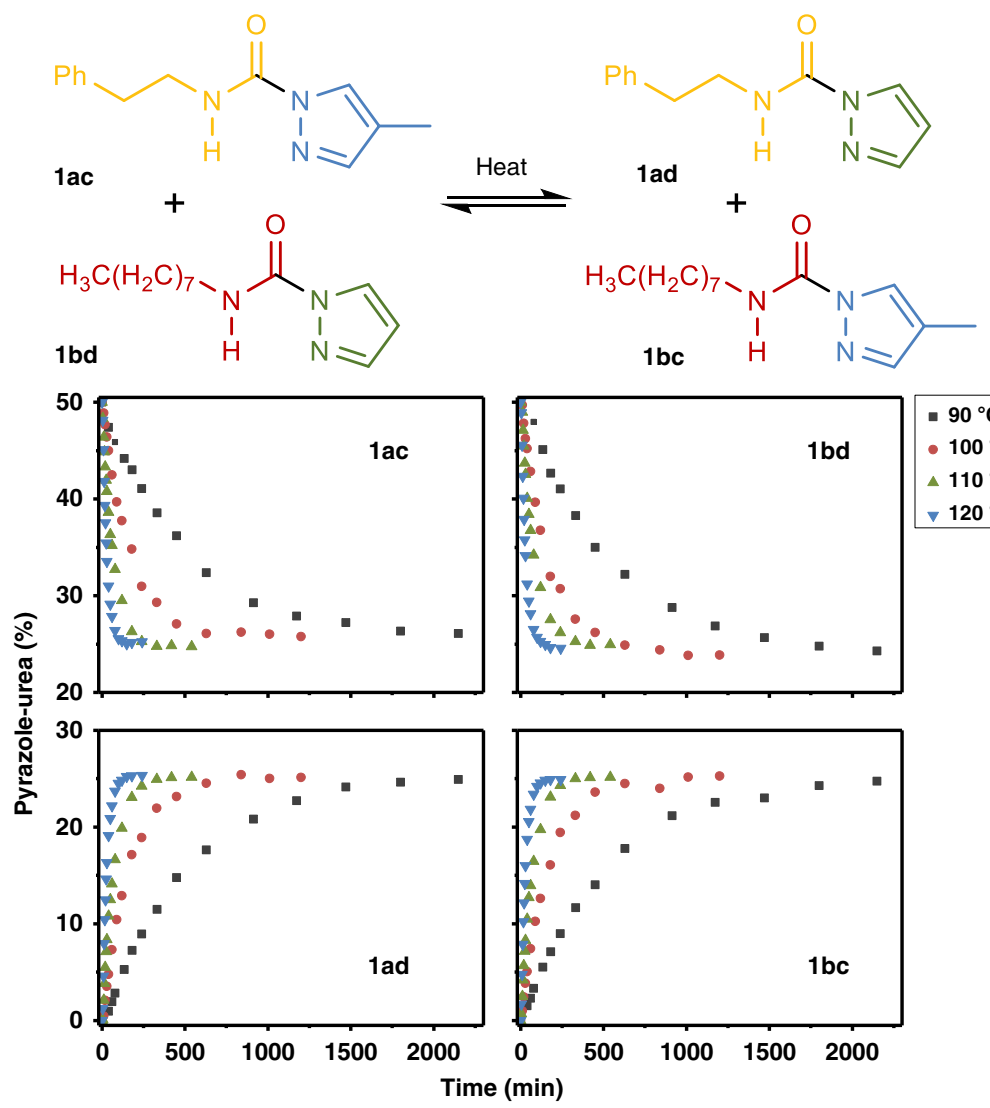

Fig. 1 The dynamic nature of pyrazole-urea bonds. a Destabilized pyrazole-urea bonds through opposed resonance and kinetically favored intramolecular hydrogen transfer. $\mathbf{b}$ The association and dissociation of $\mathbf{1} \mathbf{b c}$. $\mathbf{c}$ The model exchange reaction of $\mathbf{1 a c}$ and $\mathbf{1 b d}$ to produce $\mathbf{1}$ ad and $\mathbf{1 b c}$ as a function of time upon heating at different temperatures

Table 1 Kinetic and thermodynamic parameters of PzUBs

$\frac{k_{b}\left(303 K_{,} M^{-1} \cdot \mathbf{s}^{-1}\right)^{a}}{6.4 \times 10^{-2}}$

$6.4 \times 10^{-2}$

\section{$E_{\mathrm{a}, \mathrm{b}}\left(\mathrm{kcal} \bullet \mathrm{mol}^{-1}\right)^{\mathrm{a}}$}

11.3 $k_{\mathrm{d}}\left(363 \mathrm{~K} \mathrm{~h}^{-1}\right)^{\mathrm{b}}$

0.12

aThe reaction was performed with $\mathbf{1 b}(0.80 \mathrm{mmol})$ and $\mathbf{1 c}(0.80 \mathrm{mmol})$ in $\mathrm{CH}_{2} \mathrm{Cl}_{2}(2 \mathrm{~mL})$

bobtained from the model exchange reaction in bulk

${ }^{C}$ The dissociation of $\mathbf{1 b c}(0.21 \mathrm{mmol})$ was carried in $\mathrm{d}_{6}$-DMSO $(0.5 \mathrm{~mL})$ 
a $\left\{\begin{array}{l}\Delta G_{\text {sol } 298 \mathrm{~K}} \\ {\left[\Delta H_{\text {sol }}\right]} \\ \text { in kcal } \cdot \mathrm{mol}^{-1}\end{array}\right.$<smiles>CC(C)=CO[14C](=O)C1=C(C)C(C)=C(C)C1C</smiles><smiles>Cc1sc2c(c1C)C(=O)C(C(C)C)=N2</smiles>

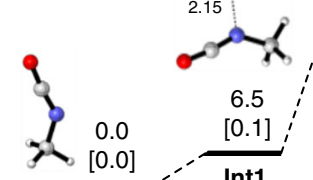
[12.8]
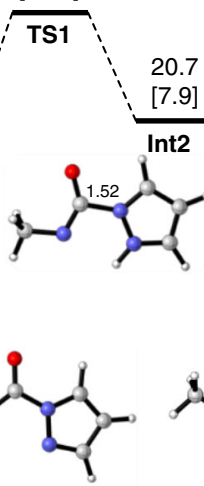

P1

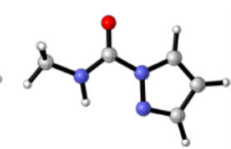

$E_{\mathrm{R}}=3.9 \mathrm{kcal} \cdot \mathrm{mol}^{-1}$

$<E_{\mathrm{R}}=5.6 \mathrm{kcal} \cdot \mathrm{mol}^{-1}<$

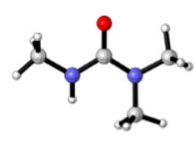

P3

Fig. 2 Theoretical investigations for the formation and dynamicity of PzUBs. a DFT calculated reaction profiles for the reaction of MeNCO and pyrazole (distances in $\AA$ ). b Resonance energies of pyrazole-urea P1, hindered urea $\mathbf{P 2}$ and normal urea $\mathbf{P 3}$

Synthesis and characterization of poly(pyrazole-ureas). With the chemistry of PzUBs in hand, we intended to fabricate dynamic covalent polymeric materials based on PzUBs. As microphase-separated polymer structures being composed of hard segments (HS) and soft segments (SS) could exhibit both good strength and high extensibility ${ }^{50}$, multiphase PPzUs were designed using multifunctional pyrazoles (4 and 5) and hexamethylene diisocyanate (HDI) as monomers (Fig. 3). The flexible poly(thio)ether chain containing cross-linker would act as the SS, while the HDI and pyrazole constitute the HS. In this design, not only the symmetric structure of HDI and aromatic planarity of pyrazole would contribute to the regular packing of the molecular chain in HS but the installation of covalent cross-linking in SS also reduce the inhibitory effect on HS crystallization.

The monomers can be simply prepared from 4pyrazolecarboxylic acid 2 within two steps through esterification reaction and thiol-ene reaction. Then, linear or cross-linked PPzUs (6 or $7 \mathrm{a}-\mathrm{c}$ ) with variable formulas were synthesized through the polymerization of multifunctional pyrazoles and HDI at room temperature in $\mathrm{CHCl} 3$ (Fig. 4a; Supplementary Figs. 15-16).

Differential scanning calorimetry (DSC) thermograms disclose that one obvious endothermic peak is detected for each of the four PPzUs (Fig. 4b; Supplementary Fig. 17), which can be assigned to the melting of partially crystallized HS from pyrazole-urea domains. Of particular note is that $\mathrm{PPzU} 7 \mathrm{c}$ with the highest cross-linking degree (average molecular weight
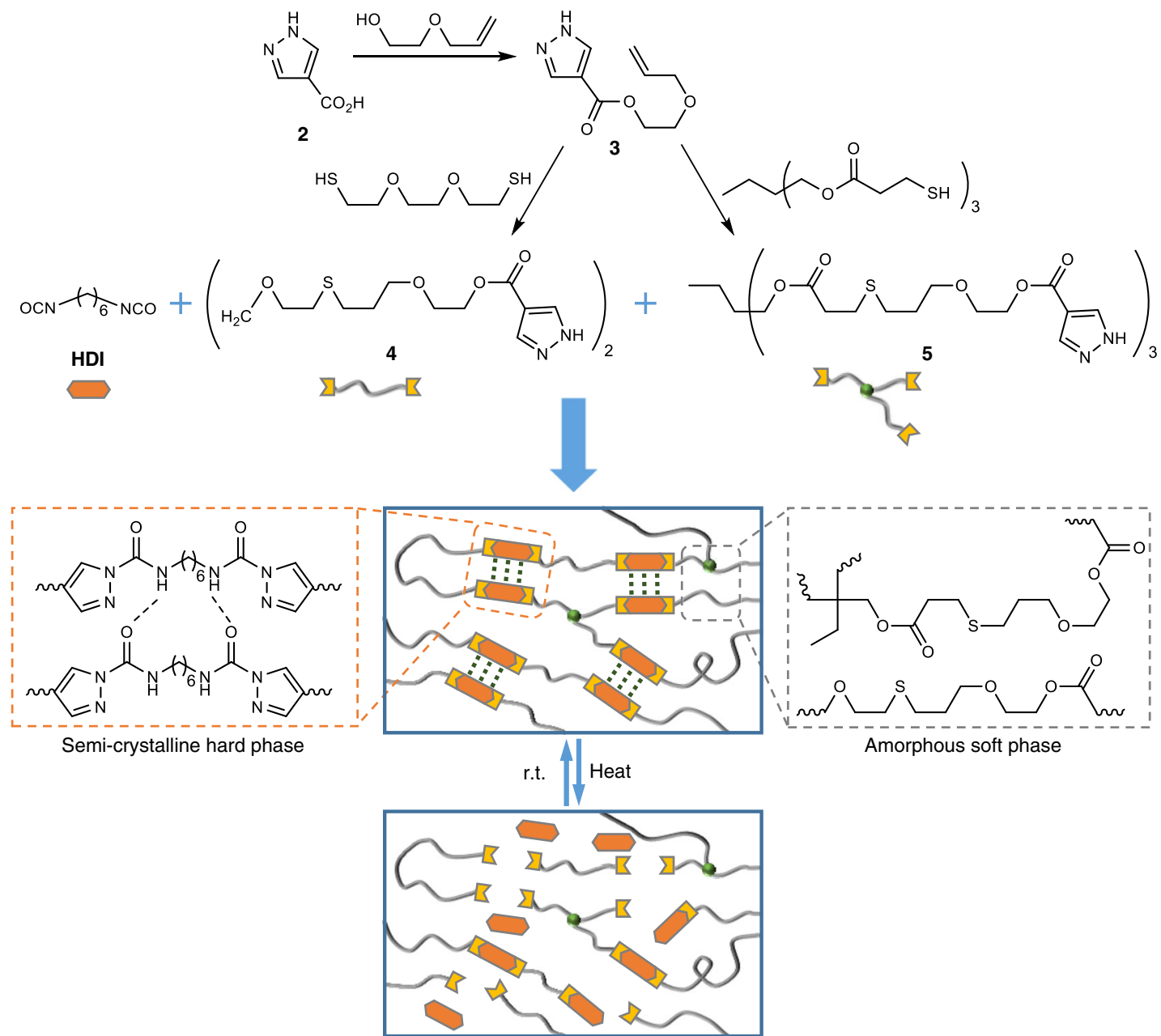

Fig. 3 Design and synthesis of dynamic multiphase poly(pyrazole-ureas) 
a
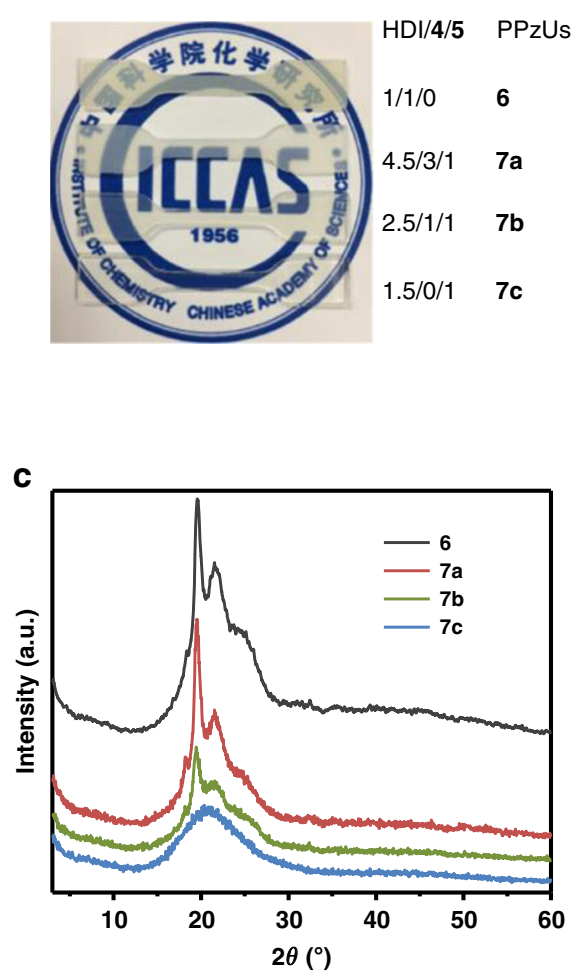

b

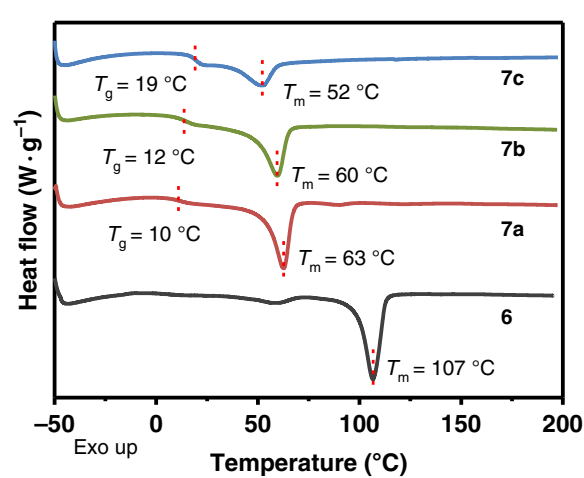

d

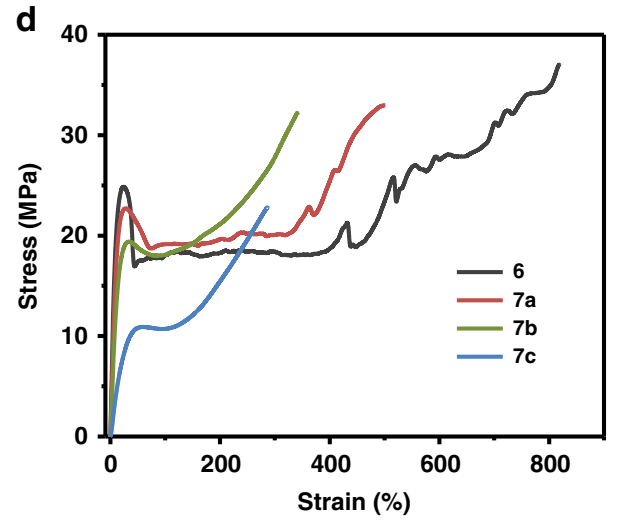

Fig. 4 Characterization of semi-crystalline poly(pyrazole-ureas). a Photographs for PPzUs ( $\mathbf{6}$ and $\mathbf{7 a}$-c $\mathbf{c}$ ) with different formulas. $\mathbf{b}$ DSC curves of the second heating runs for PPzUs. c XRD analysis of PPzUs. d Stress-strain curves of the as-prepared PPzUs

between cross-links $\left(M_{\mathrm{c}}\right)=1.7 \mathrm{~kg} \mathrm{~mol}^{-1}$, Supplementary Table 3) is still semi-crystalline although cross-linking process indeed interferes with the crystallization. This is markedly different from formerly reported ones which always exhibited amorphous behavior $^{8-33,40-43}$. With the increase of cross-linking density (Supplementary Table 3), the decrease of the intensities of crystalline peaks $\left(2 \theta=19^{\circ}\right.$ and $\left.21^{\circ}\right)$ in X-ray diffraction (XRD) patterns (Fig. 4c) and the gradual disappearance of birefringence (Supplementary Fig. 18) are both observed. Dynamic mechanical analysis reveals that $\mathrm{PPzUs}$ possess three main thermal transitions (Supplementary Fig. 19), where the first one corresponds to the glass transition $\left(T_{\mathrm{g}, S \mathrm{~S}} \approx-10^{\circ} \mathrm{C}\right)$ of SS, while the last two should be the glass transition $\left(T_{\mathrm{g}, \mathrm{HS}} \approx 30^{\circ} \mathrm{C}\right)$ and melting of $\mathrm{HS}$ $\left(T_{\mathrm{m}, \mathrm{HS}} \approx 110^{\circ} \mathrm{C}\right.$ for $\mathbf{6}, 7 \mathbf{a}-\mathbf{b} ; \approx 60^{\circ} \mathrm{C}$ for $\left.7 \mathbf{c}\right)$. Small-angle X-ray scattering (SAXS) shows that except for $\mathbf{7 c}$, other PPzUs exhibit a broad primary scattering peak with the corresponding $d$-spacing values falling into the range of $6.4-8.8 \mathrm{~nm}$ (Supplementary Fig. 20). The lack of higher orders of scattering peaks suggests that the phase separation is likely short-range correlated, which is rational in view of the fact that these PPzUs are not typical block copolymers ${ }^{51}$. Furthermore, atomic force microscopy images also proved the microphase separation between soft and hard domains (Supplementary Fig. 21). Gratifyingly, the crystallization endows PPzUs with excellent solvent resistance (Supplementary Fig. 15) and mechanical properties. Representatively, $\mathrm{PPzU} 6$ has a tensile strength $\left(\sigma_{\mathrm{b}}\right)$ of $35.9 \pm 0.9 \mathrm{MPa}$ and a strain-at-break $\left(\varepsilon_{\mathrm{b}}\right)$ of $805 \pm$ 9\% (Fig. 4d; Supplementary Table 4). In comparison with dynamic hindered polyureas ${ }^{43}$, PPzUs show excellent hydrolytic stability at $37^{\circ} \mathrm{C}$ within 6 days (Supplementary Fig. 22). These observations indicate that PPzUs are a kind of high-performance semi-crystalline polymers.

Thermal reversibility of poly(pyrazole-ureas). Next, we pay our attention to evaluate the dynamicity of PPzUs. To restrain the crystallization and increase the solubility, PPzU 8 was prepared from 1,3-bis(isocyanatomethyl)-cyclohexane (mixture of cis/trans isomers) instead of HDI. By tuning the monomer ratio, PPzU 8 can be initially depolymerized at elevated temperature and then repolymerized at low temperature (Supplementary Fig. 23), which was also observed in our recently reported dynamic poly(oximeurethanes) (POUs) ${ }^{35}$. Interestingly, after the mixture of PPzU 8 $\left(M_{\mathrm{n}}=12 \mathrm{kDa}\right)$ and POU $9\left(M_{\mathrm{n}}=58 \mathrm{kDa}\right.$, for synthesis see Supplementary Methods) was heated at $110^{\circ} \mathrm{C}$ for $3 \mathrm{~h}$ in $\mathrm{N}, \mathrm{N}$ dimethylformamide (DMF), the original peaks derived from $\mathbf{8}$ and 9 disappeared and fused into a new unimodal peak of poly (urethane-urea) $10\left(M_{\mathrm{n}}=18 \mathrm{kDa}\right.$, Fig. $\left.5 \mathrm{a}, \mathrm{b}\right)$. The successful reorganization and molecular-level blending of polyurethane and polyurea through macromolecule interchange reaction are undoubtedly attributed to the common isocyanate intermediate in the two reversible reactions. Different from traditional polymer blending methods, this artful methodology using dynamic covalent bonds provides an approach to polymer blends via the interchange reaction of polymer chains.

The plasticity of the cross-linked $\mathrm{PPzU} 7 \mathrm{c}$ was studied by temperature-dependent stress-relaxation analysis, and the results showed that higher temperature accelerates faster relaxation (Fig. $5 \mathrm{c}$ ). The characteristic relaxation time $\tau^{*}$ (where $G / G_{0}=\mathrm{e}^{-1}$ ) follows the Arrhenius law, and an activation energy $E_{\mathrm{a}, \mathrm{r}}$ of $24.5 \mathrm{kcal} \mathrm{mol}^{-1}$ was calculated (Supplementary Fig. 24), which is in good conformity with that obtained for the model compounds $\left(E_{\mathrm{a}, \mathrm{t}}=26.4 \mathrm{kcal} \mathrm{mol}^{-1}\right.$, Supplementary Fig. 7). The thermal reprocessability of the crosslinked PPzUs was characterized by uniaxial tensile testing on both pristine and recycled dogbone samples. Representatively, $\mathrm{PPzU} 7 \mathrm{c}$ can almost fully recover its mechanical properties on $\sigma_{\mathrm{b}}$ and $\varepsilon_{\mathrm{b}}$ when being remolded at $130^{\circ} \mathrm{C}$ for $30 \mathrm{~min}$, even after three cycles (Fig. 5d; Supplementary Fig. 25 and Supplementary Table 4). Noteworthily, the obvious change on yield stress and Young's modulus of the original and the first recycled samples could be observed, especially 
a
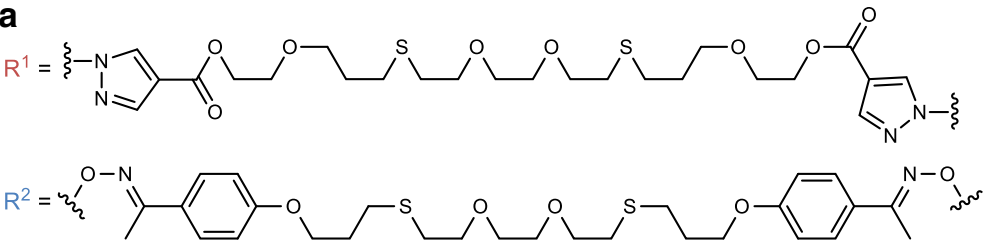

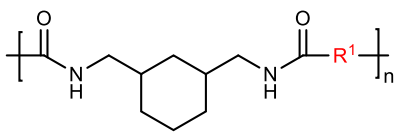

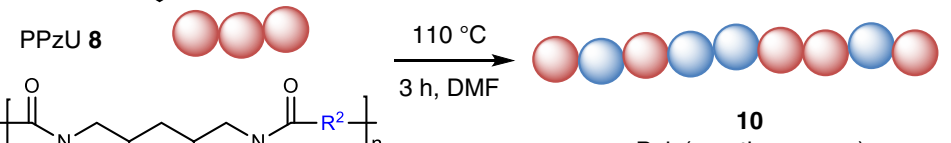

POU 9

C

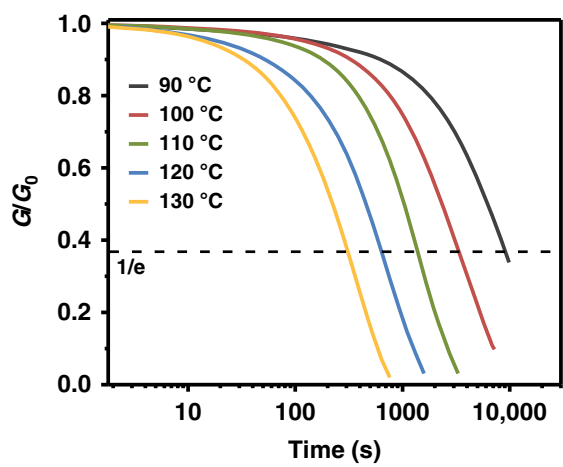

b

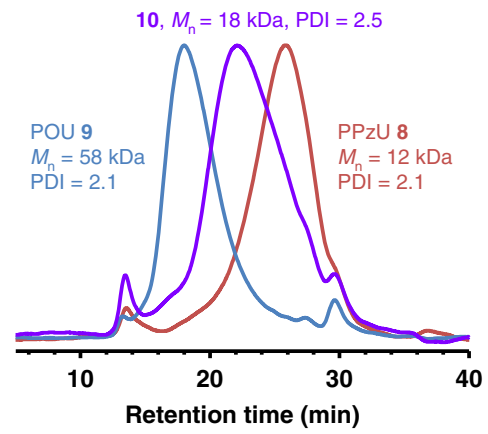

Poly(ureathane-urea)

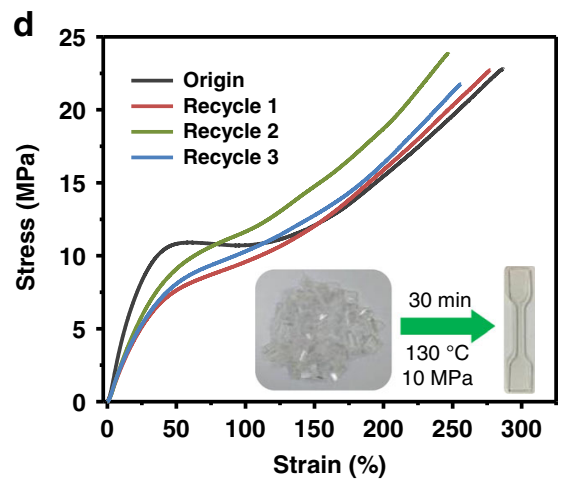

Fig. 5 Thermal reversibility of poly(pyrazole-ureas). a Macromolecular interchange reaction of PPzU 8 and POU $\mathbf{9}$ monitored by (b) gel permeation chromatography. c Normalized stress-relaxation analysis of PPzU 7c. d Recyclability of PPzU 7c evaluated by tensile test (the inset shows compression molding of 7c)

for PPzUs $7 \mathbf{a}$ and $\mathbf{7 b}$. Both the complete recovery of plateau modulus and the absence of isocyanate IR absorption for all recycled $\mathrm{PPzU}$ thermosets exclude the possibility of the irreversible breaking of PzUBs (Supplementary Figs. 19 and 26). The slight differences in tensile curves of recycled samples imply that the change of mechanical properties is more likely caused by the distinction of crystallization behavior between the original preparation process and the thermal recycling experiment, which is also supported by the SAXS and XRD experiments (Supplementary Figs. 20 and 26).

\section{Discussion}

In conclusion, we have successfully introduced the dynamic ability of pyrazole-urea bonds, which can undergo rapidly thermal dissociation or exchange reactions. Moreover, the dynamic pyrazole-urea bonds are utilized for the synthesis of a type of mechanically robust semi-crystalline dynamic polymers, poly (pyrazole-ureas). The formation of poly(pyrazole-ureas) between isocyanate and pyrazole is fast, simple, and catalyst-free at room temperature. The unique crystallization property in poly (pyrazole-urea) thermosets is rarely reported in most other highly cross-linked dynamic polymers. Considering the widely existed isocyanate-based systems, the pyrazole-urea bonds will offer a valuable platform for a range of applications, including materials design with dynamic adaptive capacity.

\section{Methods}

General information. For synthetic procedures and NMR spectra of compounds and linear polymers, see Supplementary Methods and Supplementary Figs. 27-43. For details on kinetic and thermodynamic studies, see Supplementary Note 1. Computational methods can be found in Supplementary Methods and
Supplementary Note 2. Cartesian coordinates of all molecules are given in Supplementary Note 3 .

Synthesis of cross-linked poly(pyrazole-urea) 7c. To a stirred solution of trifunctional pyrazole 5 (2.507 g, 1 equiv) in anhydrous $\mathrm{CHCl}_{3}(2.5 \mathrm{~mL})$ was added HDI $(0.634 \mathrm{~g}, 1.5$ equiv). The system was stirred for $2 \mathrm{~min}$, then poured into an aluminum mold ( $50 \mathrm{~mm} \mathrm{~L} \times 50 \mathrm{~mm} \mathrm{~W}$ ), and allowed to stand at room temperature in a desiccator for $c a .24 \mathrm{~h}$. The film was demolded, and placed under vacuum at $70{ }^{\circ} \mathrm{C}$ for $\mathrm{ca} .48 \mathrm{~h}$ to ensure complete removal of solvent. The films were kept in a desiccator before measurement.

Reprocessing experiments. The cross-linked PPzUs were cut into pieces $(\sim 2.8 \mathrm{~g})$ and placed into a rectangular mold (ca. $50 \mathrm{~mm}(\mathrm{~L}) \times 50 \mathrm{~mm}(\mathrm{~W}))$, and then hot pressed $\left(10 \mathrm{MPa} ; 140^{\circ} \mathrm{C}\right.$ for $7 \mathrm{a}, 130^{\circ} \mathrm{C}$ for $7 \mathbf{b}$ and $\left.7 \mathrm{c}\right)$ for $30 \mathrm{~min}$. The mold was cooled to room temperature for $\sim 15 \mathrm{~min}$, and the reprocessed samples were demolded.

\section{Data availability}

The data that support the findings of this study are available from the corresponding authors upon reasonable request.

Received: 12 June 2019; Accepted: 27 September 2019; Published online: 18 October 2019

\section{References}

1. Kloxin, C. J. \& Bowman, C. N. Covalent adaptable networks: smart, reconfigurable and responsive network systems. Chem. Soc. Rev. 42, 7161-7173 (2013)

2. Lutz, J.-F., Lehn, J.-M., Meijer, E. W. \& Matyjaszewski, K. From precision polymers to complex materials and systems. Nat. Rev. Mater. 1, 16024 (2016)

3. Chakma, P. \& Konkolewicz, D. Dynamic Covalent Bonds in Polymeric Materials. Angew. Chem. Int. Ed. 58, 9682-9695 (2019). 
4. Sun, H. et al. Macromolecular metamorphosis via stimulus-induced transformations of polymer architecture. Nat. Chem. 9, 817 (2017).

5. Deng, R., Derry, M. J., Mable, C. J., Ning, Y. \& Armes, S. P. Using dynamic covalent chemistry to drive morphological transitions: controlled release of encapsulated nanoparticles from block copolymer vesicles. J. Am. Chem. Soc. 139, 7616-7623 (2017).

6. Hager, M. D., Bode, S., Weber, C. \& Schubert, U. S. Shape memory polymers: past, present and future developments. Prog. Polym. Sci. 49-50, 3-33 (2015).

7. Zheng, N., Fang, Z., Zou, W., Zhao, Q. \& Xie, T. Thermoset shape-memory polyurethane with intrinsic plasticity enabled by transcarbamoylation. Angew. Chem. Int. Ed. 55, 11421-11425 (2016).

8. Zou, W., Dong, J., Luo, Y., Zhao, Q. \& Xie, T. Dynamic covalent polymer networks: from old chemistry to modern day innovations. Adv. Mater. 29, 1606100 (2017).

9. Chen, X. et al. A thermally re-mendable cross-linked polymeric material. Science 295, 1698-1702 (2002).

10. Scott, T. F., Schneider, A. D., Cook, W. D. \& Bowman, C. N. Photoinduced plasticity in cross-linked polymers. Science 308, 1615-1617 (2005).

11. Zheng, P. \& McCarthy, T. J. A surprise from 1954: siloxane equilibration is a simple, robust, and obvious polymer self-healing mechanism. J. Am. Chem. Soc. 134, 2024-2027 (2012).

12. Amamoto, Y., Otsuka, H., Takahara, A. \& Matyjaszewski, K. Self-healing of covalently cross-linked polymers by reshuffling thiuram disulfide moieties in air under visible light. Adv. Mater. 24, 3975-3980 (2012).

13. García, J. M. et al. Recyclable, strong thermosets and organogels via paraformaldehyde condensation with diamines. Science 344, 732-735 (2014).

14. Taynton, P. et al. Heat- or water-driven malleability in a highly recyclable covalent network polymer. Adv. Mater. 26, 3938-3942 (2014).

15. Billiet, S. et al. Triazolinediones enable ultrafast and reversible click chemistry for the design of dynamic polymer systems. Nat. Chem. 6, 815-821 (2014).

16. Oehlenschlaeger, K. K. et al. Adaptable Hetero Diels-Alder networks for fast self-healing under mild conditions. Adv. Mater. 26, 3561-3566 (2014).

17. Fortman, D. J., Brutman, J. P., Cramer, C. J., Hillmyer, M. A. \& Dichtel, W. R. Mechanically activated, catalyst-free polyhydroxyurethane vitrimers. J. Am. Chem. Soc. 137, 14019-14022 (2015).

18. Fox, C. H. et al. Supramolecular motifs in dynamic covalent PEG-hemiaminal organogels. Nat. Commun. 6, 7417 (2015).

19. Obadia, M. M., Mudraboyina, B. P., Serghei, A., Montarnal, D. \& Drockenmuller, E. Reprocessing and recycling of highly cross-linked ionconducting networks through transalkylation exchanges of $\mathrm{C}-\mathrm{N}$ bonds. J. Am. Chem. Soc. 137, 6078-6083 (2015).

20. Jin, K., Li, L. \& Torkelson, J. M. Recyclable crosslinked polymer networks via one-step controlled radical polymerization. Adv. Mater. 28, 6746-6750 (2016).

21. Lai, J.-C. et al. A stiff and healable polymer based on dynamic-covalent boroxine bonds. Adv. Mater. 28, 8277-8282 (2016).

22. Fuhrmann, A. et al. Conditional repair by locally switching the thermal healing capability of dynamic covalent polymers with light. Nat. Commun. 7, 13623 (2016)

23. Röttger, M. et al. High-performance vitrimers from commodity thermoplastics through dioxaborolane metathesis. Science 356, 62-65 (2017).

24. Takahashi, A., Goseki, R. \& Otsuka, H. Thermally adjustable dynamic disulfide linkages mediated by highly air-stable 2,2,6,6-tetramethylpiperidine1-sulfanyl (TEMPS) radicals. Angew. Chem. Int. Ed. 56, 2016-2021 (2017).

25. Denissen, W. et al. Chemical control of the viscoelastic properties of vinylogous urethane vitrimers. Nat. Commun. 8, 14857 (2017).

26. Yuan, Y. et al. Multiply fully recyclable carbon fibre reinforced heat-resistant covalent thermosetting advanced composites. Nat. Commun. 8, 14657 (2017).

27. Kim, S.-M. et al. Superior toughness and fast self-healing at room temperature engineered by transparent elastomers. Adv. Mater. 30, 1705145 (2018).

28. Zhang, Z. P., Rong, M. Z. \& Zhang, M. Q. Mechanically robust, self-healable, and highly stretchable "living" crosslinked polyurethane based on a reversible C-C bond. Adv. Funct. Mater. 28, 1706050 (2018).

29. Ogden, W. A. \& Guan, Z. Recyclable, strong, and highly malleable thermosets based on boroxine networks. J. Am. Chem. Soc. 140, 6217-6220 (2018).

30. Worrell, B. T. et al. Bistable and photoswitchable states of matter. Nat. Commun. 9, 2804 (2018)

31. Zhang, L. et al. A highly efficient self-healing elastomer with unprecedented mechanical properties. Adv. Mater. 31, 1901402 (2019).

32. Christensen, P. R., Scheuermann, A. M., Loeffler, K. E. \& Helms, B. A. Closedloop recycling of plastics enabled by dynamic covalent diketoenamine bonds. Nat. Chem. 11, 442-448 (2019).

33. Du, G. et al. Nacre-mimetic composite with intrinsic self-healing and shapeprogramming capability. Nat. Commun. 10, 800 (2019).

34. Rogers, M. E. \& Long, T. E. Synthetic Methods in Step-Growth Polymers. (John Wiley \& Sons, 2003)
35. Liu, W.-X. et al. Oxime-based and catalyst-free dynamic covalent polyurethanes. J. Am. Chem. Soc. 139, 8678-8684 (2017).

36. Sendijarevic, V. et al. Hydrolytic stability of toluene diisocyanate and polymeric methylenediphenyl diisocyanate based polyureas under environmental conditions. Environ. Sci. Technol. 38, 1066-1072 (2004).

37. Kaminskaia, N. V. \& Kostić, N. M. Alcoholysis of urea catalyzed by palladium (II) complexes. Inorg. Chem. 37, 4302-4312 (1998).

38. Estiu, G. \& Merz, K. M. The hydrolysis of urea and the proficiency of urease. J. Am. Chem. Soc. 126, 6932-6944 (2004).

39. Salvestrini, S., Di Cerbo, P. \& Capasso, S. Kinetics and mechanism of hydrolysis of phenylureas. J. Chem. Soc., Perkin Trans. 2, 1889-1893 (2002).

40. Wang, Z. et al. Dynamic covalent urea bonds and their potential for development of self-healing polymer materials. J. Mater. Chem. A 7, 15933-15943 (2019).

41. Hutchby, M. et al. Hindered ureas as masked isocyanates: facile carbamoylation of nucleophiles under neutral conditions. Angew. Chem. Int. Ed. 48, 8721-8724 (2009).

42. Ying, H., Zhang, Y. \& Cheng, J. Dynamic urea bond for the design of reversible and self-healing polymers. Nat. Commun. 5, 3218 (2014).

43. Ying, H. \& Cheng, J. Hydrolyzable polyureas bearing hindered urea bonds. J. Am. Chem. Soc. 136, 16974-16977 (2014).

44. Katritzky, A. R., Ramsden, C. A., Joule, J. A. \& Zhdankin, V. V. Handbook of Heterocyclic Chemistry, third edn. (Elsevier, 2010).

45. Zhang, J.-P., Zhang, Y.-B., Lin, J.-B. \& Chen, X.-M. Metal azolate frameworks: from crystal engineering to functional materials. Chem. Rev. 112, 1001-1033 (2012).

46. Staab, H. A. New methods of preparative organic chmistry IV. Syntheses using heterocyclic amides (Azolides). Angew. Chem. Int. Ed. 1, 351-367 (1962).

47. Henry, R. A. \& Dehn, W. M. Aromatic isocyanates as reagents for the identification of some heterocyclic compounds. J. Am. Chem. Soc. 71, 2297-2300 (1949).

48. Mühlebach, A. Pyrazoles-a novel class of blocking agents for isocyanates. J. Polym. Sci., Part A: Polym. Chem. 32, 753-765 (1994).

49. Greenberg, A. \& Venanzi, C. A. Structures and energetics of two bridgehead lactams and their $\mathrm{N}$ - and O-protonated forms: an ab initio molecular orbital study. J. Am. Chem. Soc. 115, 6951-6957 (1993).

50. Liff, S. M., Kumar, N. \& McKinley, G. H. High-performance elastomeric nanocomposites via solvent-exchange processing. Nat. Mater. 6, 76 (2006)

51. Li, N., Wang, L. \& Hickner, M. Cross-linked comb-shaped anion exchange membranes with high base stability. Chem. Commun. 50, 4092-4095 (2014).

\section{Acknowledgements}

The authors would like to acknowledge the financial support from Ministry of Science and Technology (2017YFB0703300), National Nature Science Foundation of China $(51522308,21572232)$ and the Chinese Academy of Sciences (QYZDB-SSW-SLH025).

\section{Author contributions}

W.-X. L., N.Z., and J.X. designed the experiments. W.-X. L. performed the experiments and data analysis. W.-X. L., N.Z., and J.X. organized and wrote the paper. Z.Y. and Z.Q. provided valuable comments for the study and paper. DFT calculations were carried out by W.-X. L. with the help of L.Z. and S.L. All authors took part in the discussion of the experiment results.

\section{Competing interests}

The authors declare no competing interests.

\section{Additional information}

Supplementary information is available for this paper at https://doi.org/10.1038/s41467019-12766-6.

Correspondence and requests for materials should be addressed to L.Z., N.Z. or J.X.

Peer review information Nature Communications thanks Hesheng Xia and the other, anonymous, reviewer(s) for their contribution to the peer review of this work. Peer reviewer reports are available.

Reprints and permission information is available at http://www.nature.com/reprints

Publisher's note Springer Nature remains neutral with regard to jurisdictional claims in published maps and institutional affiliations. 
(c) (i) Open Access This article is licensed under a Creative Commons Attribution 4.0 International License, which permits use, sharing, adaptation, distribution and reproduction in any medium or format, as long as you give appropriate credit to the original author(s) and the source, provide a link to the Creative Commons license, and indicate if changes were made. The images or other third party material in this article are included in the article's Creative Commons license, unless indicated otherwise in a credit line to the material. If material is not included in the article's Creative Commons license and your intended use is not permitted by statutory regulation or exceeds the permitted use, you will need to obtain permission directly from the copyright holder. To view a copy of this license, visit http://creativecommons.org/ licenses/by/4.0/.

(C) The Author(s) 2019 